\title{
Theoretical energy performance evaluation of different single stage vapour compression refrigeration configurations using $R 1234 y f$ and $R 1234 z(E)$ as working fluids
}

\author{
Francisco Molés ${ }^{1, a}$, Joaquín Navarro-Esbrí ${ }^{\text {a }}$ Bernardo Peris ${ }^{\mathrm{a}}$, \\ Adrián Mota-Babiloni ${ }^{\mathrm{b}}$, Ángel Barragán-Cervera ${ }^{\mathrm{a}}$ \\ ${ }^{a}$ ISTENER Research Group. Department of Mechanical Engineering and Construction, \\ Campus de Riu Sec s/n, University Jaume I, E12071, Castellón (Spain). \\ ${ }^{\mathrm{b}}$ Departamento de Ingeniería Química y Nuclear, Universidad Politécnica de Valencia, \\ Camino de Vera 14, Valencia (Spain).
}

\begin{abstract}
R1234yf and R1234ze(E) have been proposed as alternatives for R134a in order to work with low GWP refrigerants, but this replacement results generally in a decrease of the performance. For this reason, it is interesting to explore ways to improve the system performance using these refrigerants. In this paper, a comparative study in terms of energy performance of different single stage vapour compression configurations using $\mathrm{R} 1234 \mathrm{yf}$ and R1234ze(E) as working fluids has been carried out. The most efficient configuration is the one which uses an expander or an ejector as expansion device. On the other hand, using an internal heat exchanger in a cycle which replaces the expansion valve by an expander or an ejector could produce a detrimental effect on the COP. However, for all the configurations the introduction of an internal heat exchanger produces a significant increment on the cooling capacity.
\end{abstract}

Keywords: single stage; refrigeration; R1234yf; R1234ze(E); energy efficiency.

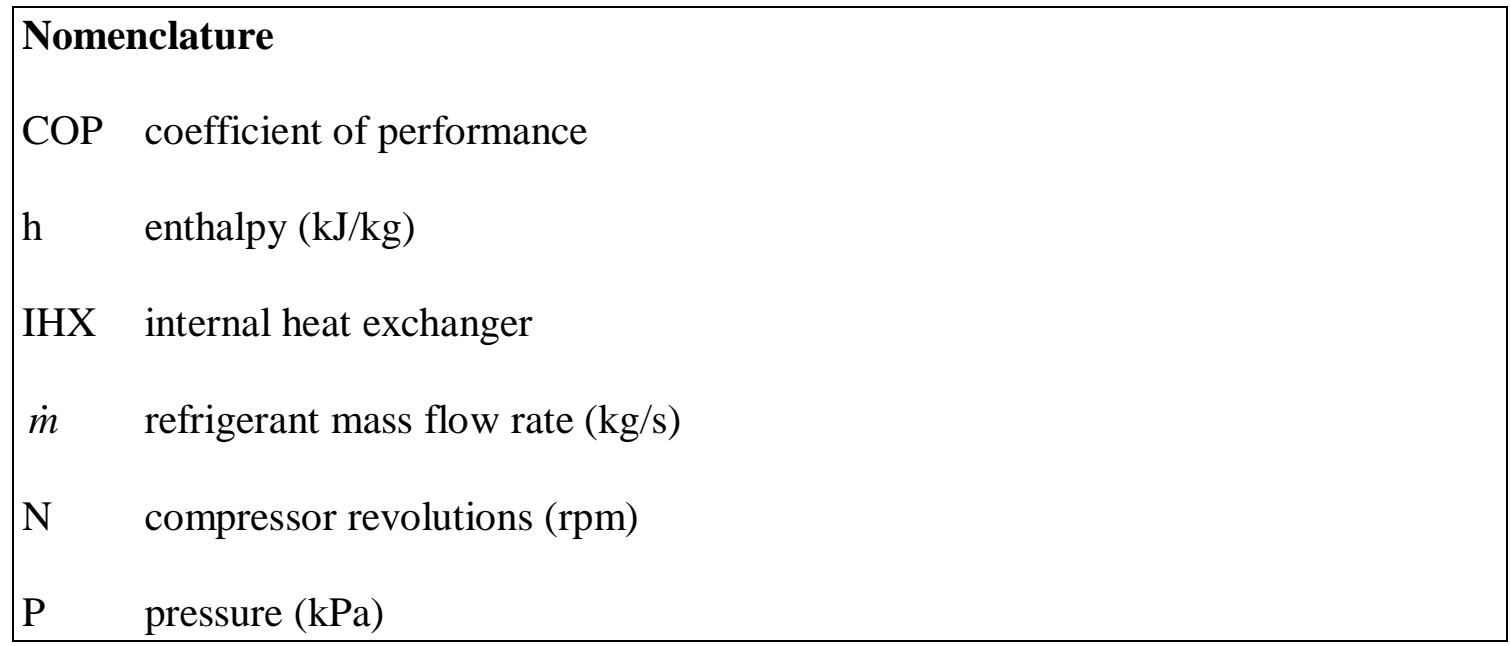

${ }^{1}$ Corresponding Author:

Tel: +34 964387529; fax: +34964728106.

E-mail address: molesf@uji.com 
Q thermal power $(\mathrm{kW})$

$\mathrm{T} \quad$ temperature $(\mathrm{K})$

V compressor volume $\left(\mathrm{m}^{3}\right)$

W electric power $(\mathrm{kW})$

Greek symbols

$\varepsilon \quad$ internal heat exchanger effectiveness

$\eta \quad$ efficiency

$\rho \quad$ density $\left(\mathrm{kg} / \mathrm{m}^{3}\right)$

Subscripts

c compressor

d diffuser

e ejector

em electromechanical

g global

is isentropic

$\mathrm{k} \quad$ condenser

n nozzle

o evaporator

s suction

V volumetric

x expander

\section{Introduction}

Nowadays, chlorofluorocarbon (CFC) and hydrochlorofluorocarbon (HCFC) refrigerants have been replaced by hydrofluorocarbon (HFC) refrigerants, with zero ozone depletion potential (ODP), according to the Montreal Protocol [1]. However, 
many HFC refrigerants have high global warming potential (GWP) values and they are considered as greenhouse gases under the Kyoto Protocol [2]. As a result, efforts are made in order to search alternative refrigerant for high GWP refrigerants replacement. R1234yf and R1234ze(E) (henceforth it will be referred simply as R1234ze) have been proposed [3] as alternative refrigerants for R134a, which has a GWP of 1430 and is extensively used in refrigeration and air conditioning, especially in mobile air conditioning (MAC). Both refrigerants have an ODP value of zero [4], a GWP value of 4 and 6, respectively [5,6], low toxicity and mild flammability [7]. Despite this, some authors [8,9] have reported reductions in the coefficient of performance (COP) and the cooling capacity when using R1234yf as a drop-in replacement for R134a. On the other hand, for R1234ze the results showed a higher COP but lower cooling capacity [10], making R1234ze unsuitable as drop-in replacement due to the requirement of a significantly higher compressor swept volume to achieve the same cooling capacity than R134a.

In this context, various manners of increasing the COP in a vapour compression refrigeration system can be highlighted, such as the increase of the refrigerating effect in the evaporator by means of an internal heat exchanger (IHX) [11], the use of expansion devices which allow to reduce the losses in the expansion stage such as ejectors [12], or even the use of expanders to reduce system energy consumption by expansion work recovery [13]. The use of these devices has motivated the study of different configurations in order to improve the cycle efficiency. Navarro-Esbrí et al. [14] analysed experimentally the influence of an internal heat exchanger on the performance of a vapour compression system using R1234yf as a drop-in replacement for $\mathrm{R} 134 \mathrm{a}$, reporting reductions between $6-13 \%$ in cooling capacity and COP when $\mathrm{R} 134 \mathrm{a}$ is replaced by R1234yf, although the presence of an IHX can help to reduce these reductions. Harrell et al. [15] performed an experiment of an ejector as an expansion device in a system using R134a as refrigerant, reporting improvements on the COP over standard cycles between $3.9 \%$ and $7.6 \%$. Li et al. [16] analyse an ejectorexpansion refrigeration cycle using R1234yf as refrigerant, highlighting that the cycle outperforms the standard one, especially under extreme working conditions. Lawrence et al. [17-20] conducted an experimental and analytical investigation of two-phase ejector cycles using low pressure refrigerants R134a and R1234yf, concluding that when compared to a single evaporation temperature expansion valve cycle the ejector cycle showed maximum COP improvements of 6\% with R1234yf and 5\% with R134a. Robinson et al. [21] have reported that an expander increases the COP up to $15 \%$ when applied to conventional R22 and R134a systems.

Therefore, the aim of this work is to evaluate theoretically the energy performance of six single stage vapour compression refrigeration configurations using low GWP refrigerants R1234yf and R1234ze as working fluids, including some complex configurations that mix the presence of an IHX with an ejector or an expander. The rest of the paper is organized as follows. In Section 2, the proposed configurations are presented. In Section 3, the results are shown and discussed. Finally, in Section 4, the main conclusions of the paper are summarized.

\section{Configurations}


This paper focuses on evaluating single stage vapour compression cycle configurations, being the configurations analysed the followings:

a) Basic cycle (BC)

b) Cycle with internal heat exchanger (IHXC)

c) Ejector-expansion refrigeration cycle (EERC)

d) Ejector-expansion with internal heat exchanger cycle (EEIHXC)

e) Expansion work recovery cycle (WRC)

f) Expansion work recovery with internal heat exchanger cycle (WRIHXC)

In Table 1, the operating conditions taken as basis of comparison are presented. For all calculations the same constant refrigerant volumetric flow rate has been taken. The characterization of each of the configurations has been done under steady state conditions and the refrigerant properties have been evaluated using software REFPROP [22]. In Table 2, the main components characterization equations are presented. The ejector was modelled using the thermodynamic model developed by Kornhauser [23], an iterative model commonly used in the literature with equations based on the conservation of mass, momentum, and energy, and it assumes homogeneous equilibrium at all points in the ejector. Below, each configuration is presented in detail. The efficiencies of the main components, as expander and ejector, have been extracted from the literature [24]. The software used to do the simulations is MATLAB [25].

Table 1. Operating conditions.

Table 2. Components characterization.

\subsection{Basic cycle (BC)}

The first configuration analysed is shown with its P-h diagram in Fig. 1. The basic cycle consists of a compressor, a condenser, an expansion valve and an evaporator.

Fig. 1. Basic cycle (BC).

\subsection{Cycle with internal heat exchanger (IHXC)}

The IHXC, whose diagram is shown in Fig. 2, is a modification of the basic cycle with the introduction of an internal heat exchanger. The main objective of the internal heat exchanger is to reduce the temperature of the subcooled refrigerant at the condenser outlet while increasing that of the superheated refrigerant at the evaporator outlet. On the other hand, due to the superheating effect that the internal heat exchanger causes, the work needed at the compressor will tend to increase, the discharge temperature also increases and the refrigerant mass flow rate decreases. 
Fig. 2. Cycle with internal heat exchanger (IHXC).

\subsection{Ejector-expansion refrigeration cycle (EERC)}

Typical vapour compression refrigeration cycle uses thermostatic expansion valve, which is assumed an isenthalpic process. Isenthalpic process causes a decrease in the COP due to the energy loss in the throttling process. An ejector can be used to reduce the irreversibilities in the throttling process.

In the Ejector-Expansion Refrigeration Cycle (EERC), shown in Fig. 3, the working fluid of the primary and the secondary flows are in liquid and vapour phase respectively, while the working fluid at the ejector outlet is in the two-phase region. The working principle of an ejector is based on high pressure fluid (primary flow) used to induce fluid from low pressure (secondary fluid) to a higher pressure at diffuser outlet.

Fig. 3. Ejector-expansion refrigeration cycle (EERC).

\subsection{Ejector-expansion with internal heat exchanger cycle (EEIHXC)}

The previous cycle could be modified introducing an internal heat exchanger, as shown in Fig. 4. The internal heat exchanger is placed to increase the refrigerating effect and ensure that the vapour at the compressor inlet is superheated vapour.

Fig. 4. Ejector-expansion with internal heat exchanger cycle (EEIHXC).

\subsection{Expansion work recovery cycle (WRC)}

The main difference between this configuration, Fig. 5, and the Basic Cycle configuration resides in the expansion stage. The thermostatic expansion device is substituted by an expander or turbine. The expander contributes to decrease the system power consumption and increase the refrigerating effect; therefore, it decreases the total irreversibility in the cycle increasing the COP.

Fig. 5. Expansion work recovery cycle (WRC).

\subsection{Expansion work recovery with internal heat exchanger cycle (WRIHXC)}

This configuration consists of an Expansion Work Recovery Cycle which also includes an internal heat exchanger, allowing a major increase of the refrigerating effect. Fig. 6 shows the diagram with the corresponding stages representation in a P-h diagram. 
Fig. 6. Expansion work recovery with internal heat exchanger (WRIHXC).

\section{Results and discussion}

This section presents the main results of the energetic simulation carried out using the proposed operating conditions, Table 1, and the characterization presented in Table 2. As exposed in the introduction, refrigerants R1234yf and R1234ze have been developed as alternatives for R134a. Therefore, the results show the variations on the COP and cooling capacity, $\mathrm{Q}_{\mathrm{o}}$, of each configuration working with R1234yf/R1234ze taking as reference the Basic Cycle working with R134a, as indicated in Eq. (1) and Eq. (2).

$$
\begin{gathered}
\% C O P=\left(\frac{C O P_{R 1234 y f / R 1234 z e}-C O P_{R 134 a, B C}}{C O P_{R 134 a, B C}}\right) \cdot 100 \\
\% Q_{0}=\left(\frac{Q_{0 R 1234 y f / R 1234 z e}-Q_{0 R 134 a, B C}}{Q_{0 R 134 a, B C}}\right) \cdot 100
\end{gathered}
$$

Fig. 7 shows the COP and $\mathrm{Q}_{0}$ values evolution varying the evaporating temperature. Attending to the Basic Cycle, it is observed that the COP of the installation working with R1234yf is 5\% to 7\% lower than the COP of the installation working with R134a, agreeing with experimental results from other authors [8,9]. For the R1234ze, attending to the Basic Cycle, the COP of the installation is almost equal than the COP of the installation working with R134a. The rest of configurations present increments on the $\mathrm{COP}$ with respect to the Basic Cycle working with R134a for both fluids. These increments on the COP are greater at low evaporating temperatures. The most efficient configuration is the one which uses an expander or an ejector as an expansion device, with increments of $9 \%$ to $15 \%$ for R1234yf and $11 \%$ to $20 \%$ for R1234ze on the COP with respect to the Basic Cycle working with R134a. The introduction of an internal heat exchanger in the WRC and EERC configurations does not result in an increase on the COP; however for $\mathrm{BC}$ configuration the introduction of an internal heat exchanger produce an increment of the COP, reaching the values of a Basic Cycle working with R134a for the R1234yf, as concluded experimentally by Navarro-Esbrí et al. [14]. Focusing on $\mathrm{Q}_{\mathrm{o}}$, for a Basic Cycle there is a reduction of $7 \%$ when using R1234yf instead of R134a, and $25 \%$ to $27 \%$ when using R1234ze. For all the configurations the introduction of an internal heat exchanger results on an increment of the $\mathrm{Q}_{0}$. The variations on the $\mathrm{Q}_{\mathrm{o}}$ decrease with the evaporating temperature.

Fig. 7. $\mathrm{COP}$ and $\mathrm{Q}_{\mathrm{o}}$ variation versus evaporating temperature.

Fig. 8 shows the influence of the condensing temperature on the COP and $\mathrm{Q}_{0}$ values. The COP of the Basic Cycle working with R1234f is $4 \%$ to $8 \%$ lower than that obtained with R134a, while for R1234ze the COP is almost equal than the obtained with R134a. For the rest of configurations the COP increases. These increments on the COP grow with the condensing temperature. Attending to the $\mathrm{Q}_{0}$, for a Basic Cycle there is a reduction of $4 \%$ to $7 \%$ when using R1234yf instead of R134a, while for R1234ze the Qo 
is $26 \%$ lower than the obtained with R134a. As occurs for the evaporating temperature, for all configurations the introduction of an internal heat exchanger results on an increment of the $Q_{o}$. The variations on the $Q_{o}$ increase with the condensing temperature.

Fig. 8. $\mathrm{COP}$ and $\mathrm{Q}_{\mathrm{o}}$ variation versus condensing temperature.

In Fig. 9, the variation of the COP and $\mathrm{Q}_{\mathrm{o}}$ versus internal heat exchanger effectiveness has been plotted in order to show the effect of this parameter in WRIHXC, EEIHXC and IHXC configurations. For WRIHXC and EEIHXC the internal heat exchanger effectiveness has low influence, with variations in values of the COP of $9 \%$ to $12 \%$ for R1234yf and $11 \%$ to $15 \%$ for R1234ze. Furthermore, increasing the internal heat exchanger effectiveness does not result in an increment of the COP. However, for IHXC the internal heat exchanger effectiveness has a high influence on the COP variation, with values of $-6 \%$ to $6 \%$ for R1234yf and $-1 \%$ to $8 \%$ for R1234ze. For values of the internal heat exchanger effectiveness below 45\%, the IHXC working with R1234yf presents reductions on the COP with respect to the Basic Cycle working with R134a. But for values of the internal heat exchanger effectiveness above $45 \%$, the IHXC working with R1234yf presents increments on the COP with respect to the Basic Cycle working with R134a. It has to be noted that internal heat exchanger effectiveness greater than $45 \%$ could result in high discharge temperatures. For example, for condensing temperature of $330 \mathrm{~K}$ and evaporating temperature of $260 \mathrm{~K}$, an internal heat exchanger effectiveness of $50 \%$ would result on a discharge temperature of $367 \mathrm{~K}$, while an IHX effectiveness of $90 \%$ would result on a discharge temperature of $390 \mathrm{~K}$. Respect to $\mathrm{Q}_{\mathrm{o}}$, the internal heat exchanger effectiveness has a great influence on all the configurations, increasing the $\mathrm{Q}_{\mathrm{o}}$, as expected.

Fig. 9. COP and $\mathrm{Q}_{0}$ variation versus internal heat exchanger effectiveness.

For EERC and EEIHXC configurations, diffuser efficiency has the highest influence on the COP improvement [23]; then, the influence of the diffuser efficiency on the COP and $\mathrm{Q}_{\mathrm{o}}$ variations is studied and shown in Fig. 10. For values of the diffuser efficiency below 70\%, the EEIHXC presents COP variations greater than the EERC for R1234yf, while this behaviour occurs for R1234ze below $60 \%$ of diffuser efficiency. Therefore, the effect of the internal heat exchanger on the COP not only depends on the internal heat exchanger effectiveness and the working temperatures, but also depends on the ejector efficiencies. Focusing on $\mathrm{Q}_{0}$, increasing the diffuser efficiency produce an increment on the $\mathrm{Q}_{\mathrm{o}}$ variation for both configurations.

Fig. 10. COP and $Q_{0}$ variation versus ejector diffuser efficiency.

To study the influence of the expander efficiency on the COP and $\mathrm{Q}_{0}$ variation on WRC and WRIHXC configurations, the $\mathrm{COP}$ and $\mathrm{Q}_{\mathrm{o}}$ variation versus global expander efficiency is shown in Fig. 11. The global expander efficiency is the composition of the different expander efficiencies (volumetric, isentropic and electromechanical). For 
values of the global expander efficiency above $40 \%$, WRC presents greater COP variation than WRIHXC. The expander efficiency has negligible effect on the $\mathrm{Q}_{0}$.

Fig. 11. COP and $\mathrm{Q}_{\text {o }}$ variation versus expander global efficiency.

\section{Conclusions}

In this paper a comparative study in terms of energy performance of different single stage vapour compression configurations using R1234yf and R1234ze as working fluids has been carried out, taking as reference the Basic Cycle working with R134a. The main conclusions of this work are the following ones.

The most efficient configuration is the one which uses an expander or an ejector as an expansion device, with increments of $9 \%$ to $15 \%$ for R1234yf and $11 \%$ to $20 \%$ for $\mathrm{R} 1234 z e$ on the COP with respect to the Basic Cycle working with R134a. The use of an internal heat exchanger in a configuration using an expander or an ejector, although always produces an increment on the cooling capacity, could produce a detrimental effect on the COP of the configuration depending on the working temperatures, internal heat exchanger effectiveness and efficiencies of the expander or ejector. However, the main disadvantage of these configurations is the increase in the complexity of the system that difficult to put into practice this type of configurations, and the increase of the costs.

Attending to the Basic Cycle, the COP of an installation working with R1234yf is $4 \%$ to $8 \%$ lower than that obtained using R134a, being also $\mathrm{Q}_{\mathrm{o}}$ about $4 \%$ to $7 \%$ lower. For R1234ze the COP of the installation is almost equal than the obtained with R134a, but the $\mathrm{Q}_{0}$ is about $25 \%$ to $27 \%$ lower. However, introducing an internal heat exchanger produces an increment on the COP and $\mathrm{Q}_{\mathrm{o}}$. For values of internal heat exchanger effectiveness above $45 \%$, the COP of an IHXC working with R1234yf is greater than the COP of a BC working with R134a, but high IHX effectiveness values could increase the discharge temperature up to not admissible values.

It should be noted that the aim of this work is to compare the relative performance of different configurations, for evaluate theoretically the viability of these configurations. Future studies should be carried in order to validate experimentally the results obtained in this paper and obtain values of the main energy performance parameters, such as $\mathrm{COP}$ and cooling capacity, for a particular configuration and working fluid.

\section{References}

[1] United Nations Environment Program (UNEP), Montreal Protocol on Substances that Deplete the Ozone Layer, Final Act, United Nations, New York, 1997.

[2] Kyoto Protocol, Report of the Conference of the Parties, United Nations Framework Convention on Climate Change (UNFCCC), 1997. 
[3] M.O. McLinden, A.F. Kazakov, J.S. Brown, P.A. Domanski, A thermodynamic analysis of refrigerants: possibilities and tradeoffs for low-GWP refrigerants, International Journal of Refrigeration (2013), doi: 10.1016/j.ijrefrig.2013.09.032.

[4] World Meteorological Organization (WMO), Scientific Assessment of Ozone Depletion: 2006, Global Ozone, Research and Monitoring Project - Report 50, Geneva, Switzerland, 2007.

[5] V.C. Papadimitriou, R.K. Talukdar, R.W. Portmann, A.R. Ravishankara, J.B. Burkholder, $\mathrm{CF} 3 \mathrm{CF}=\mathrm{CH} 2$ and $(\mathrm{Z})-\mathrm{CF} 3 \mathrm{CF}=\mathrm{CHF}$ : Temperature dependent $\mathrm{OH}$ rate coefficients and global warming potentials, Physical Chemistry and Chemical Physics 10 (2008), $808-820$.

[6] O.J. Nielsen, M.S. Javadi, A. Sulbak, M.D. Hurley, T.J. Wallington, R. Singh, Atmospheric chemistry of $\mathrm{CF} 3 \mathrm{CF}=\mathrm{CH} 2$ : Kinetics and mechanisms of gas-phase reactions with $\mathrm{Cl}$ atoms, $\mathrm{OH}$ radicals, and O3. Chemical Physics Letters 439 (2007), 18 -22 .

[7] M. Koban, HFO-1234yf Low GWP Refrigerant LCCP Analysis, SAE Technical Paper 2009-01-0179, doi: 10.4271/2009-01-0179.

[8] C. Zilio, J.S. Brown, G. Schiochet, A. Cavallini, The refrigerant R1234yf in air conditioning systems, Energy 36 (2011), 6110 - 6120.

[9] J. Navarro-Esbrí, J.M. Mendoza-Miranda, A. Mota-Babiloni, A. Barragán-Cervera, J.M. Belman-Flores, Experimental analysis of R1234yf as a drop-in replacement for $\mathrm{R} 134 \mathrm{a}$ in a vapour compression system, International Journal of Refrigeration 36 (2012), $870-880$.

[10] D. Leighton, Y. Hwang, R. Radermacher, Modelling of household refrigerator performance with low global warming potential alternative refrigerants, ASHRAE Transactions 118 (2012), 658 - 665.

[11] P.A. Domanski, D.A. Didion, J.P. Doyle, Evaluation of suction-line/liquid-line heat exchanger in the refrigeration cycle, International Journal of Refrigeration 17 (1994), $487-493$.

[12] K. Sumeru, H. Nasution, F.N. Ani, A review on two-phase ejector as an expansion device in vapor compression refrigeration cycle, Renewable and Sustainable Energy Reviews 16 (2012), 4927 - 4937.

[13] A. Subiantoro, K.T. Ooi, Economic analysis of the application of expanders in medium scale air-conditioners with conventional refrigerants, R1234yf and $\mathrm{CO}_{2}$, International Journal of Refrigeration 36 (2013), 1472 - 1482.

[14] J. Navarro-Esbrí, F. Molés, A. Barragán-Cervera, Experimental analysis of the internal heat exchanger influence on a vapour compression system performance working with R1234yf as a drop-in replacement for R134a, Applied Thermal Engineering 59 (2013), 153 - 161. 
[15] G. S. Harrel, A.A. Kornhauser, Performance test of two-phase ejector, In: Proceedings of the $30^{\text {th }}$ intersociety energy conversion engineering conference, Orlando, Florida, USA, 1995, 49 - 53.

[16] H. Li, F. Cao, X. Bu, L. Wang, X. Wang, Performance characteristics of R1234yf ejector-expansion refrigeration cycle, Applied Energy 121 (2014), 96 - 103.

[17] N. Lawrence, S. Elbel, Experimental investigation of a two-phase ejector cycle suitable for use with low-pressure refrigerants R134a and R1234yf, International Journal of Refrigeration 38 (2014), 310 - 322.

[18] N. Lawrence, S. Elbel, Experimental and analytical investigation of two-phase ejector air-conditioning cycles using low-pressure refrigerants R134a and R1234yf, SAE technical paper, 2013, doi:10.4271/2013-01-1495.

[19] N. Lawrence, Analytical and experimental investigation of two-phase ejector cycles using low-pressure refrigerants, Ph.D. Thesis, University of Illinois, 2013.

[20] N. Lawrence, S. Elbel, Experimental and analytical investigation of automotive ejector air-conditioning cycles using low-pressure refrigerants, International Refrigeration and Air Conditioning Conference, 2012, Paper 1169.

[21] D.M. Robinson, E.A. Groll, Efficiencies of transcritical $\mathrm{CO}_{2}$ cycles with and without an expansion turbine, International Journal of Refrigeration 21 (1998), 577 589.

[22] E.W. Lemmon, M.L. Huber, M.O. McLinden, REFPROP, NIST Standard Reference Database 23, v.8, National Institute of Standards, Gaithersburg, MD, USA, 2007.

[23] A.A. Kornhauser, The use of an ejector as refrigerant expander, In: Proceedings of the USN/IIR-Purdue refrigeration conference, West Lafayette, IN, USA, 1990, p. 10 9 .

[24] Fang Liu, Eckhard A. Groll, Study of ejector efficiencies in refrigeration cycles, Applied Thermal Engineering 52 (2013), 360 - 370.

[25] MathWorks - Mathlab and simulink for technical computing. <http://www.mathworks.com/>. 

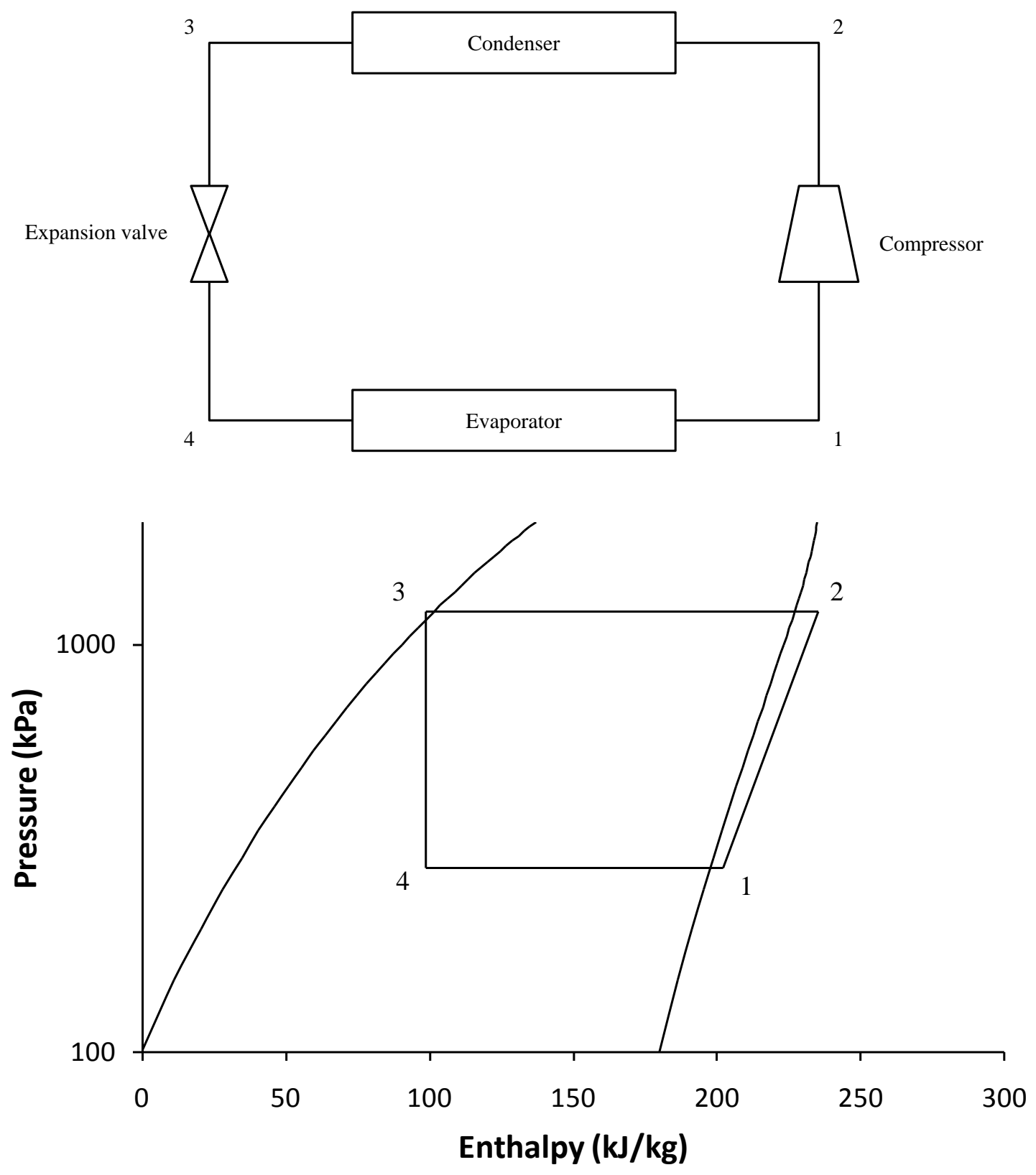

Fig. 1. Basic cycle (BC). 

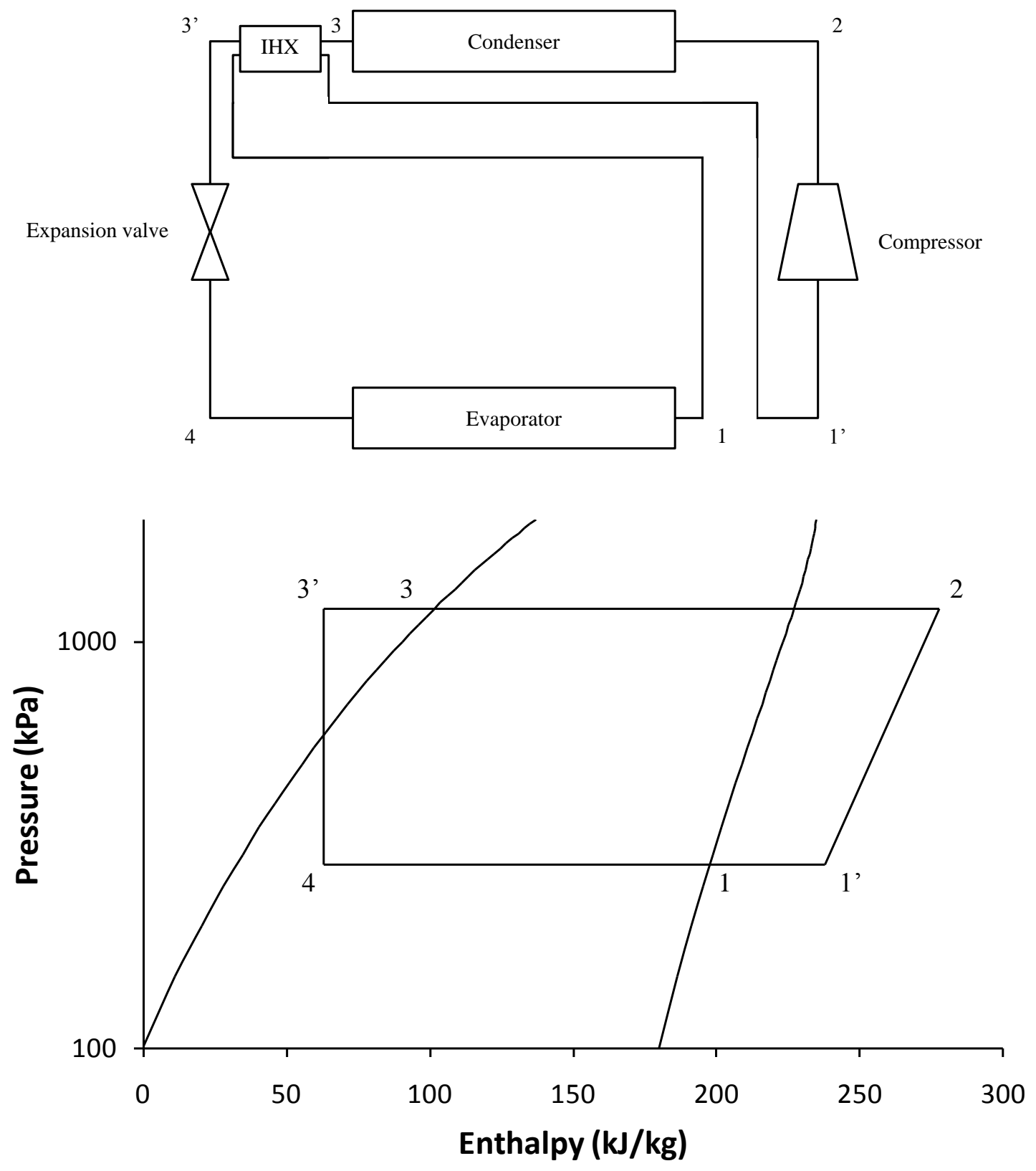

Fig. 2. Cycle with internal heat exchanger (IHXC). 

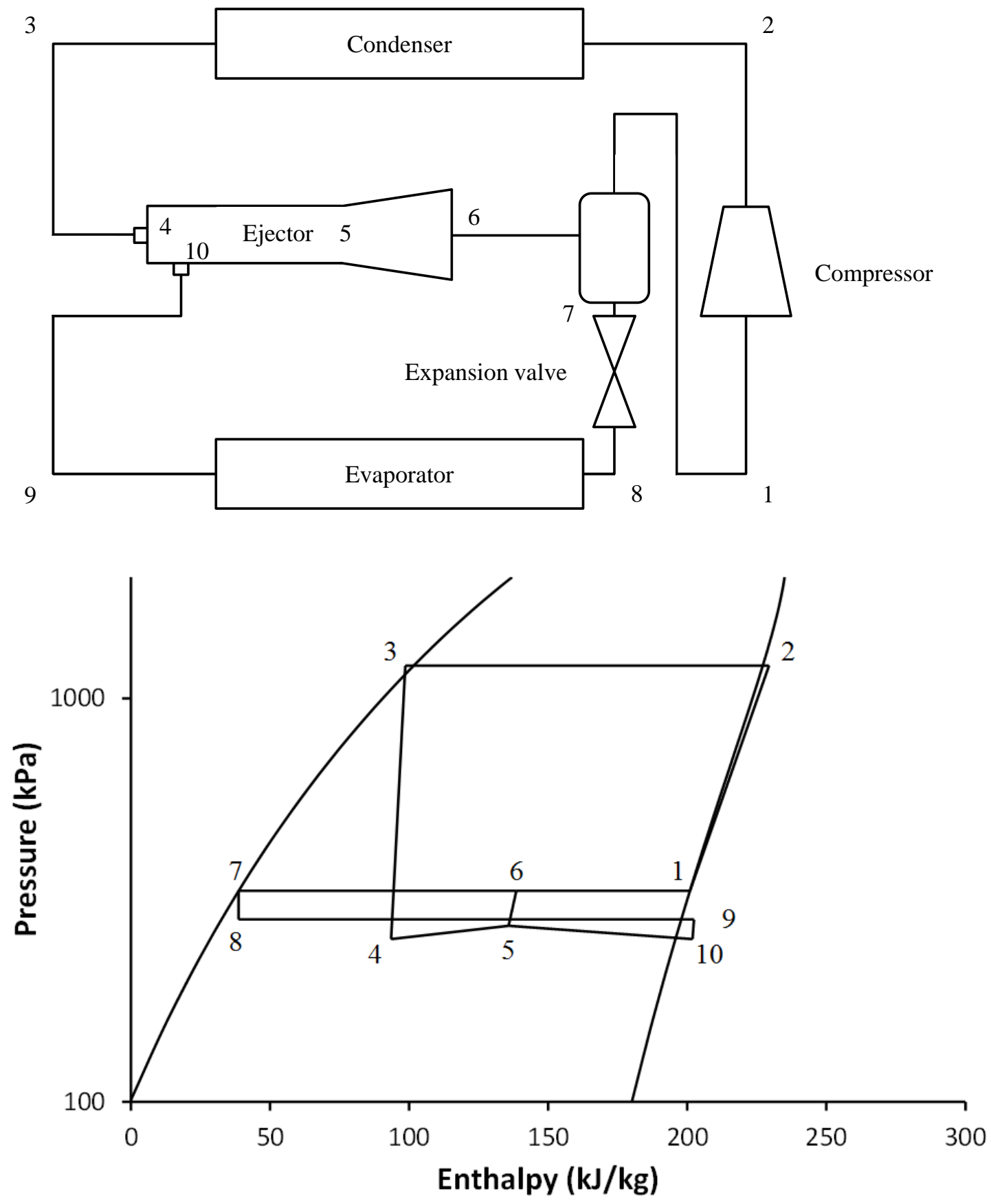

Fig. 3. Ejector-expansion refrigeration cycle (EERC). 

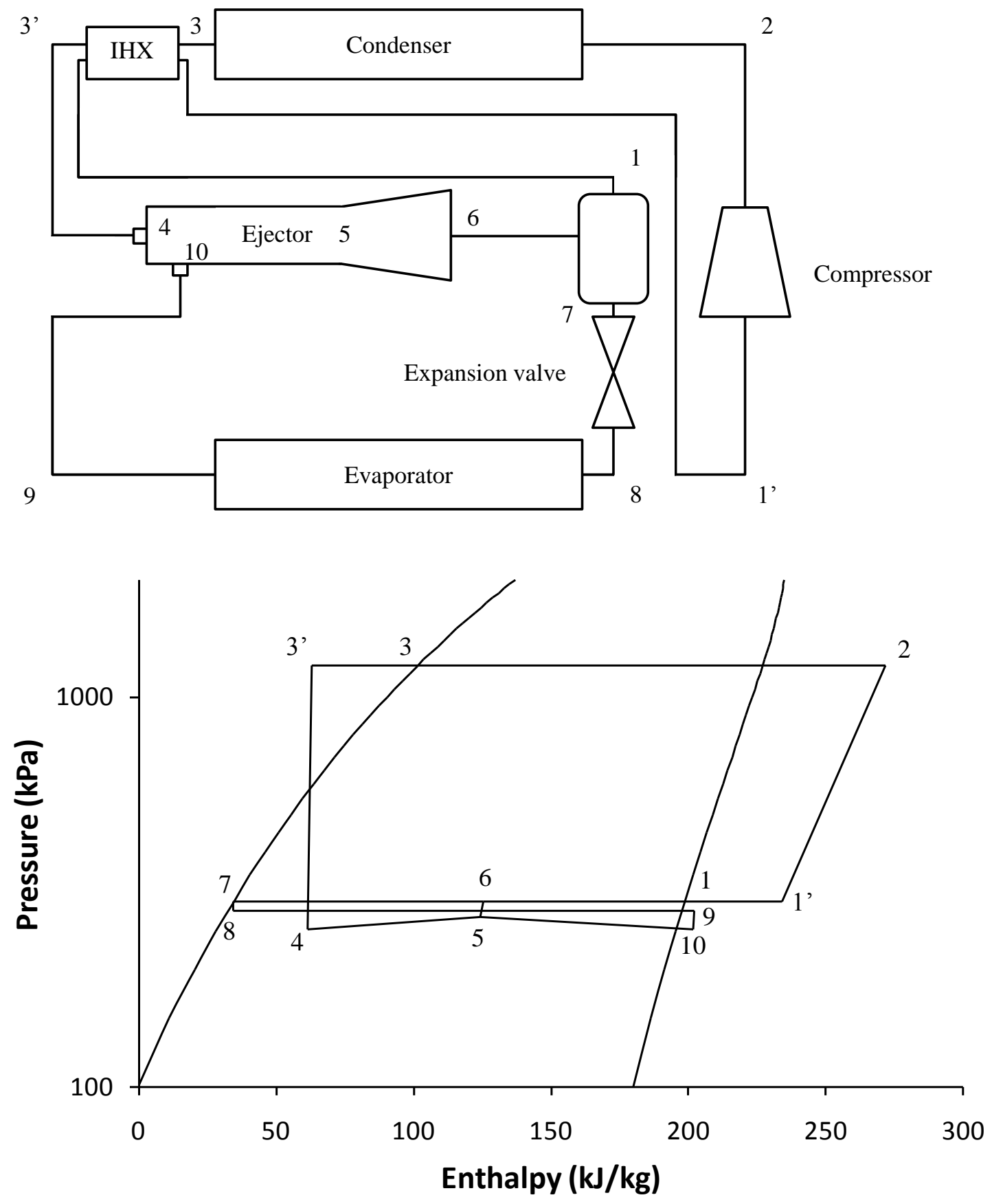

Fig. 4. Ejector-expansion with internal heat exchanger cycle (EEIHXC). 

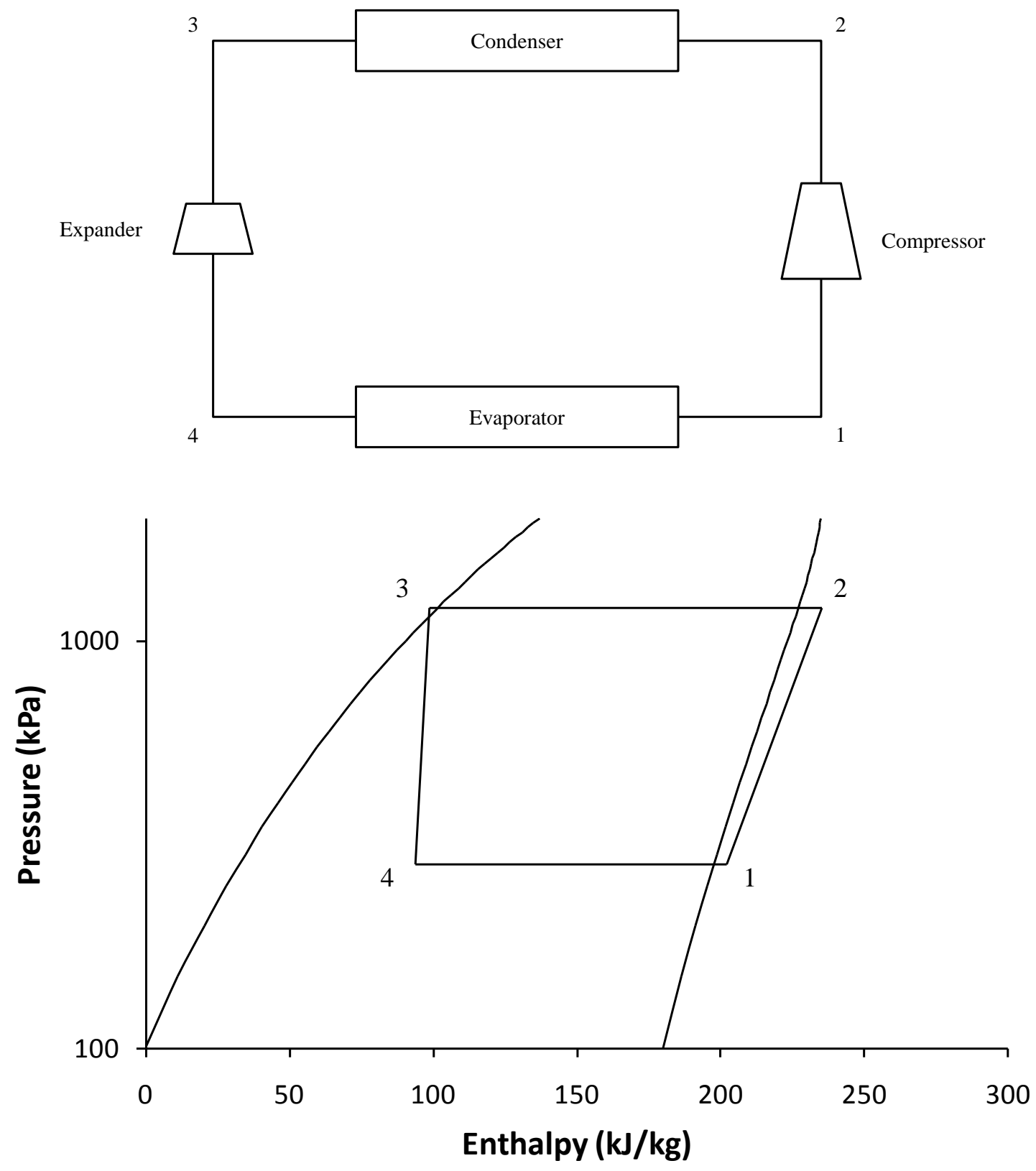

Fig. 5. Expansion work recovery cycle (WRC). 

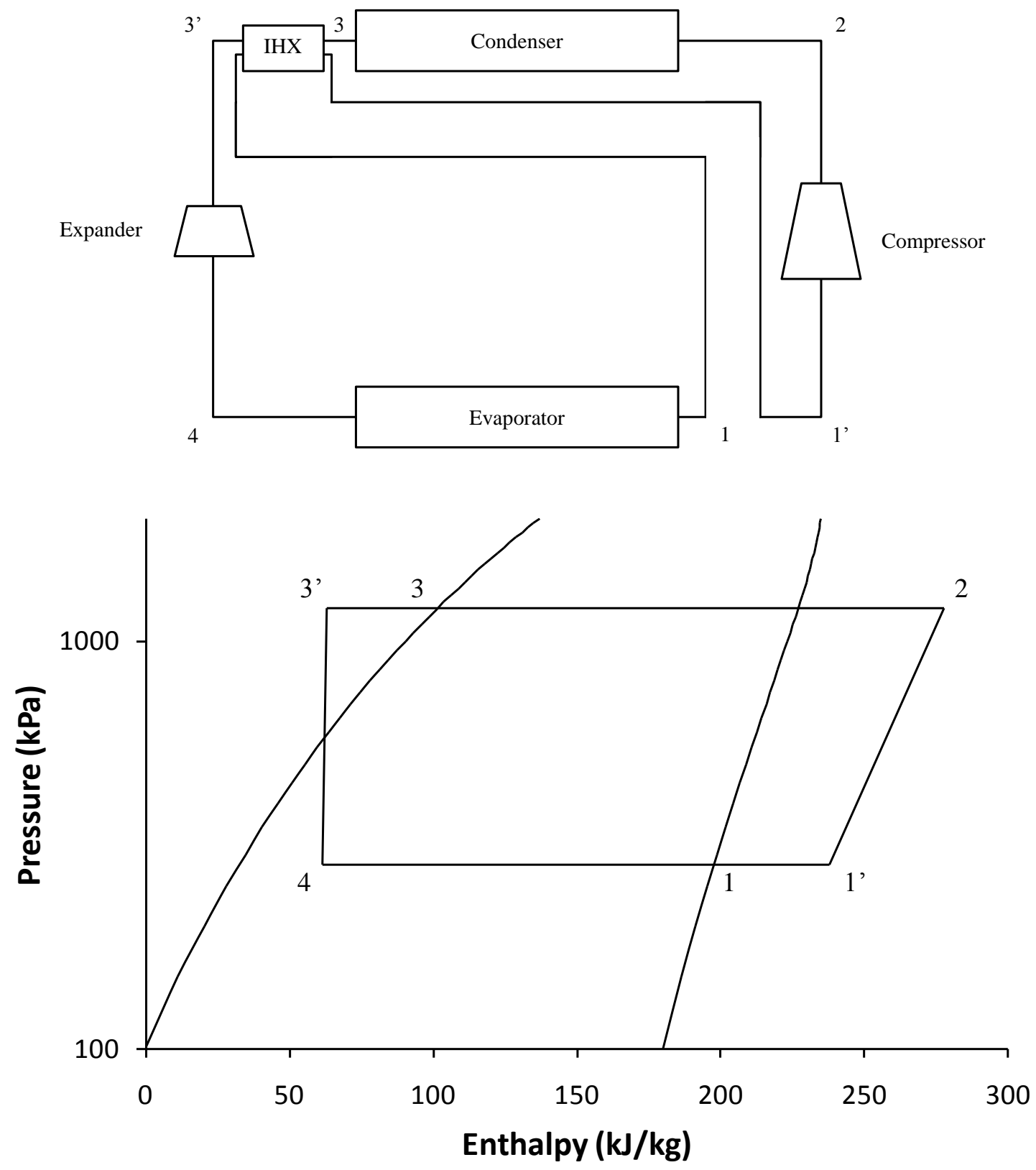

Fig. 6. Expansion work recovery with internal heat exchanger (WRIHXC). 

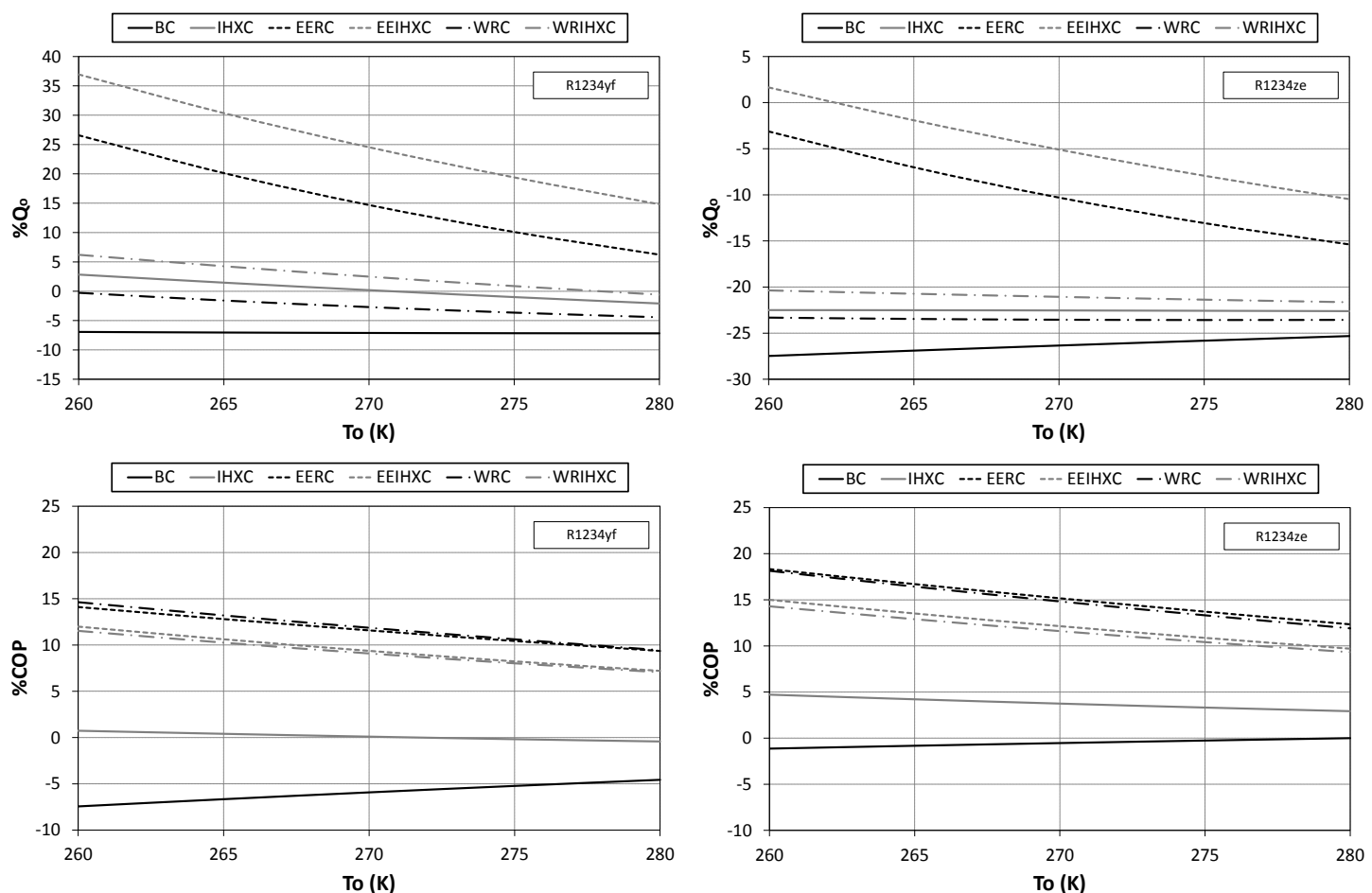

Fig. 7. $\mathrm{COP}$ and $\mathrm{Q}_{\mathrm{o}}$ variation versus evaporating temperature. 

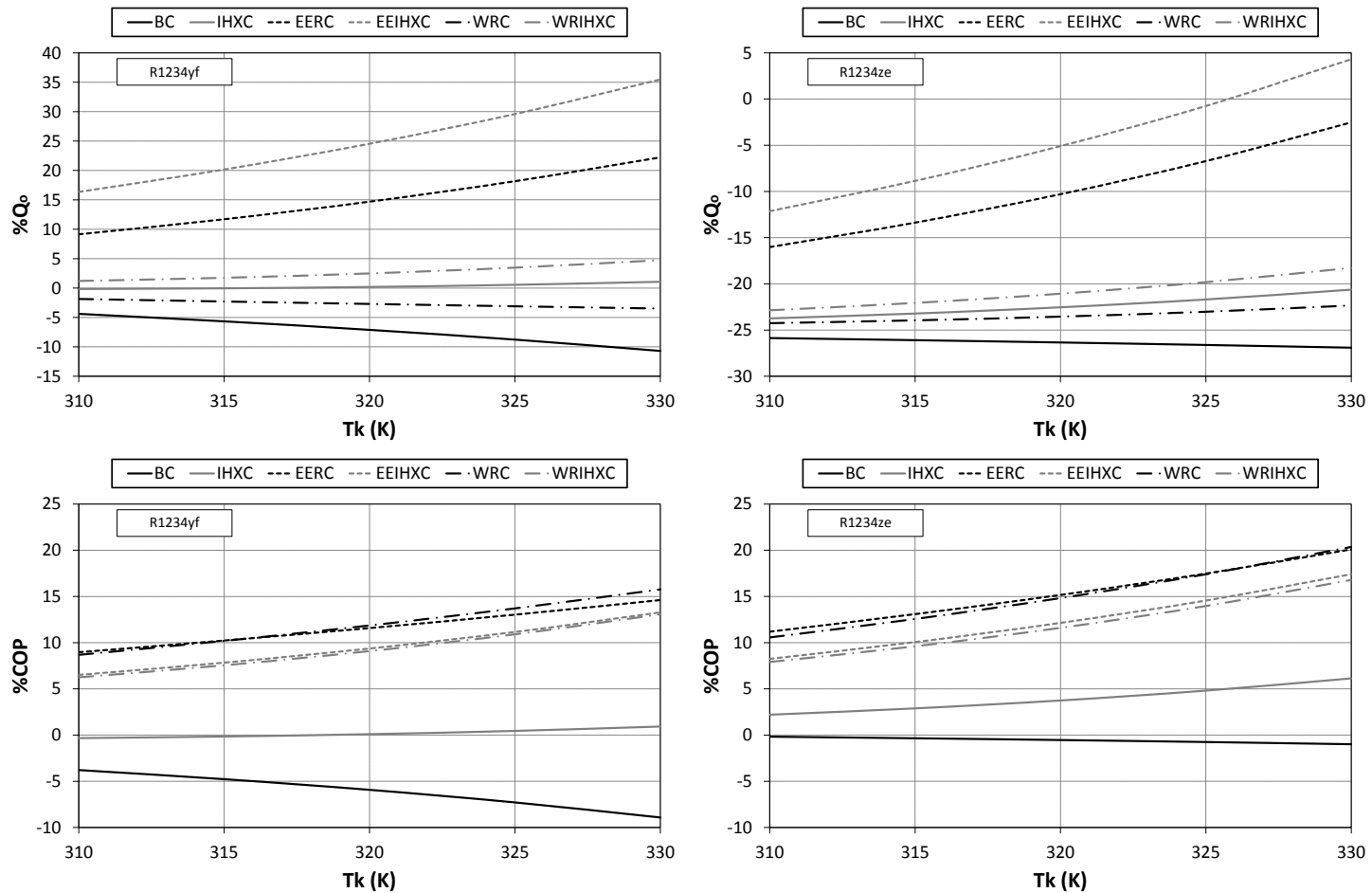

Fig. 8. $\mathrm{COP}$ and $\mathrm{Q}_{\mathrm{o}}$ variation versus condensing temperature. 

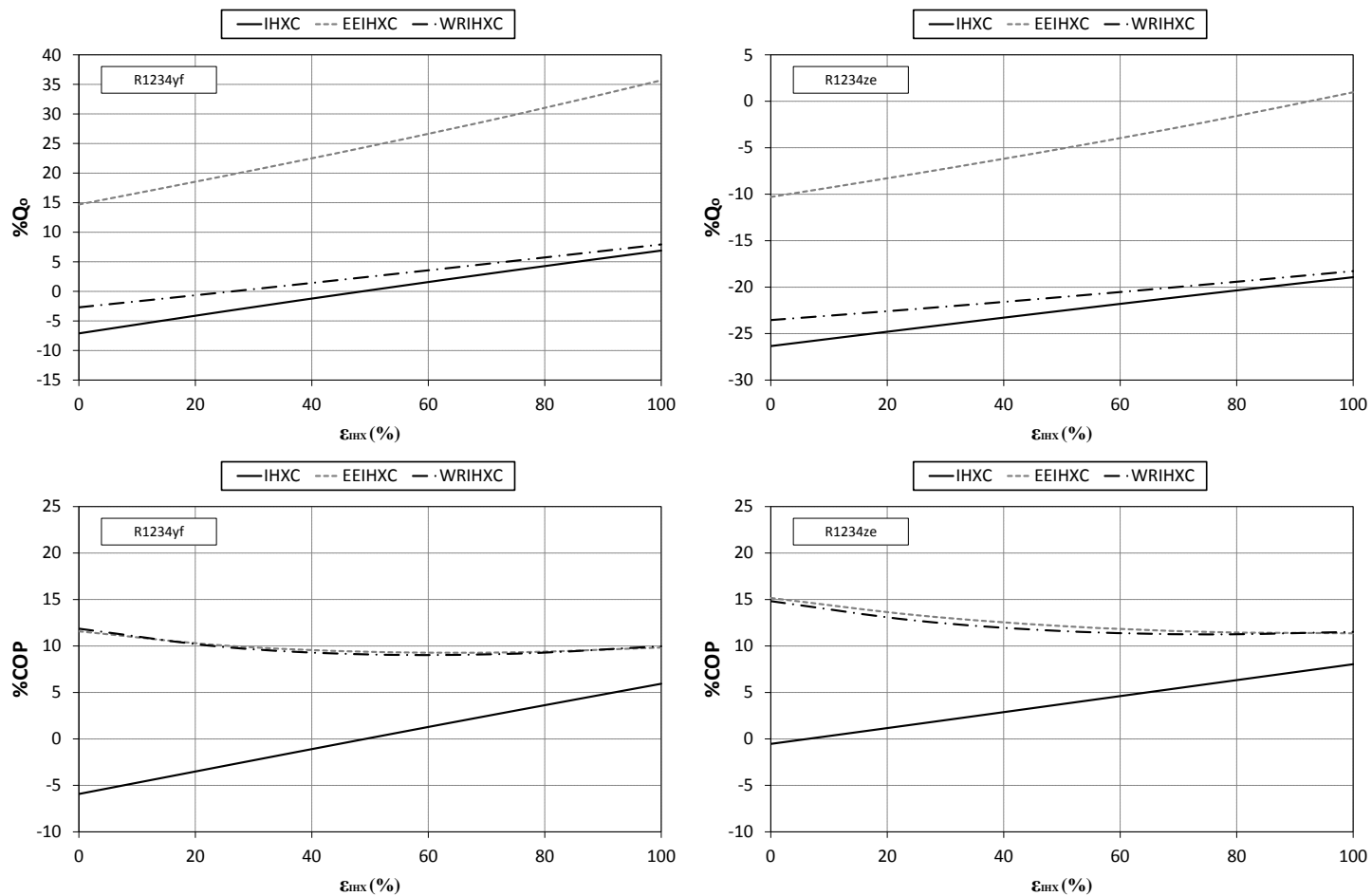

Fig. 9. COP and $Q_{0}$ variation versus internal heat exchanger effectiveness. 

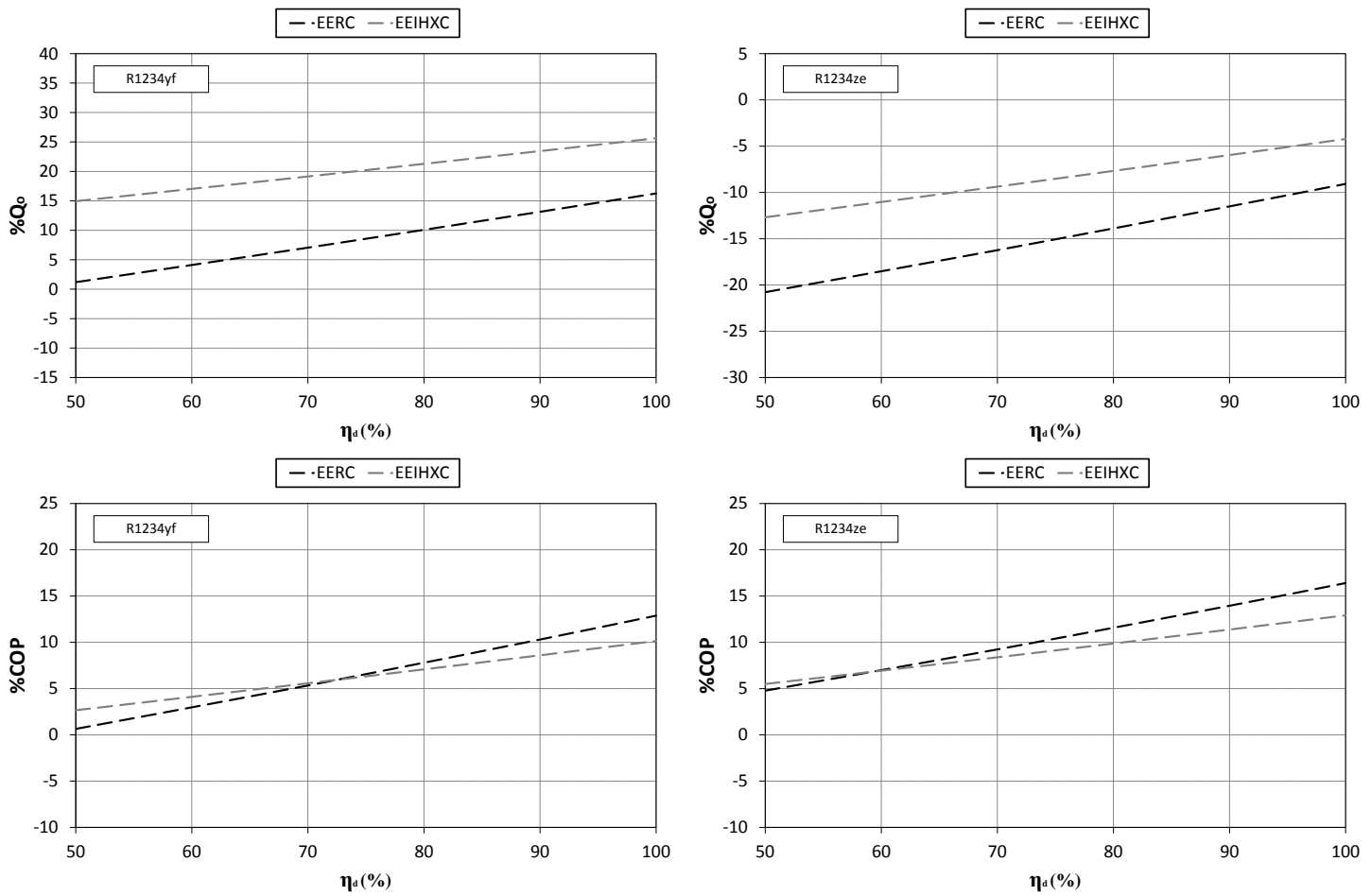

Fig. 10. COP and $Q_{0}$ variation versus ejector diffuser efficiency. 

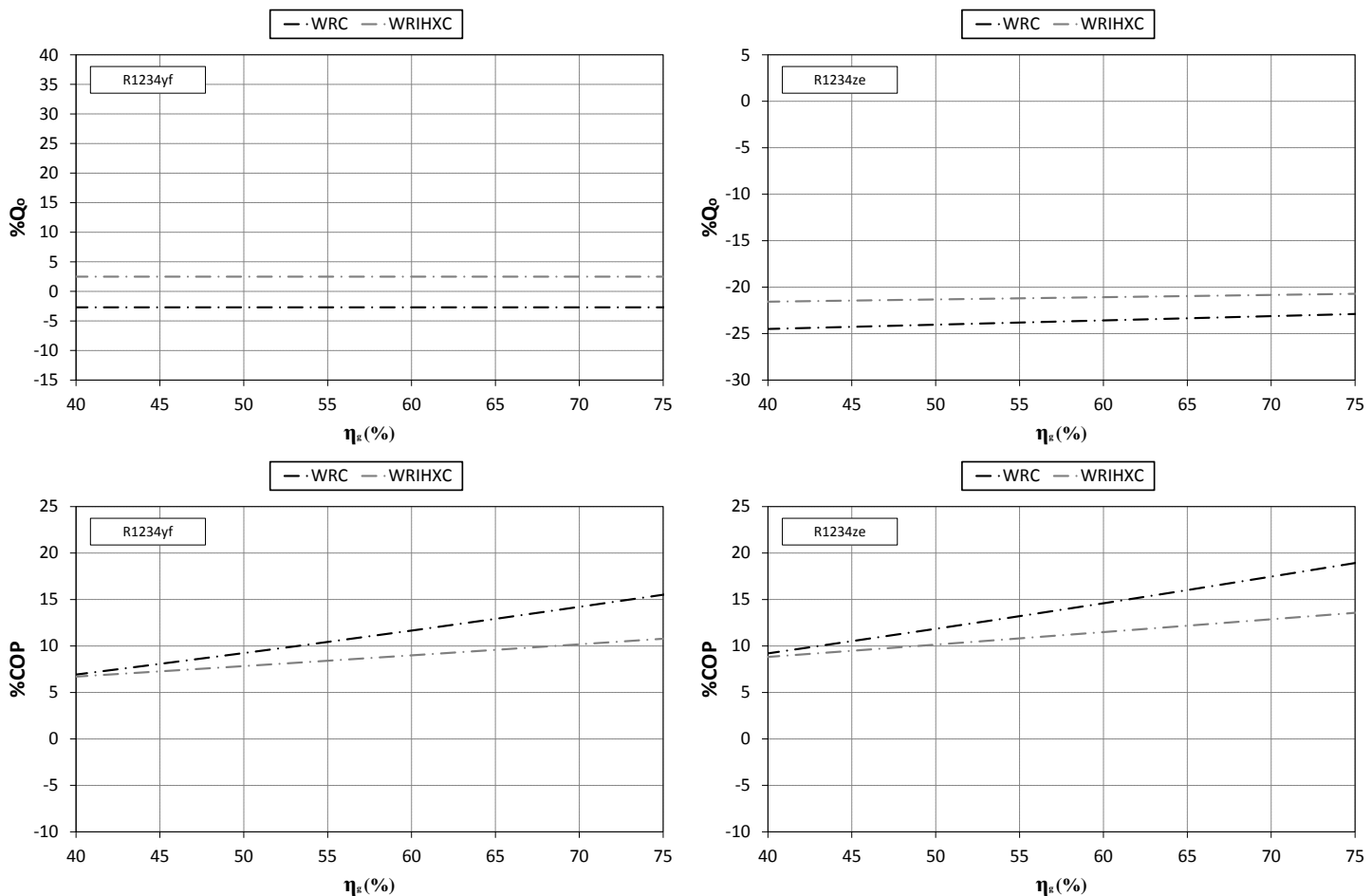

Fig. 11. COP and $\mathrm{Q}_{\mathrm{o}}$ variation versus expander global efficiency. 


\section{FIGURE CAPTIONS}

Fig. 1. Basic cycle (BC).

Fig. 2. Cycle with internal heat exchanger (IHXC).

Fig. 3. Ejector-expansion refrigeration cycle (EERC).

Fig. 4. Ejector-expansion with internal heat exchanger cycle (EEIHXC).

Fig. 5. Expansion work recovery cycle (WRC).

Fig. 6. Expansion work recovery with internal heat exchanger (WRIHXC).

Fig. 7. COP and $\mathrm{Q}_{0}$ variation versus evaporating temperature.

Fig. 8. COP and $\mathrm{Q}_{0}$ variation versus condensing temperature.

Fig. 9. COP and $\mathrm{Q}_{0}$ variation versus internal heat exchanger effectiveness.

Fig. 10. COP and $Q_{0}$ variation versus ejector diffuser efficiency.

Fig. 11. COP and $Q_{0}$ variation versus expander global efficiency. 
Table 1. Operating conditions.

Parameters

Numeric values

Condensing temperature $\left(T_{k}\right)$ $320 \mathrm{~K}$

Evaporating temperature $\left(T_{o}\right)$ $270 \mathrm{~K}$

Superheating degree $5 \mathrm{~K}$

Subcooling degree $2 \mathrm{~K}$

IHX effectiveness ( $(\varepsilon)$ $50 \%$

Efficiencies $\left(\eta_{v, c}, \eta_{i s, c}, \eta_{v, x}, \eta_{i s, x}, \eta_{n, e}, \eta_{s, e}\right)$ $80 \%$

Efficiencies $\left(\eta_{\mathrm{em}, \mathrm{c}}, \eta_{\mathrm{em}, \mathrm{x}}, \eta_{\mathrm{d}, \mathrm{e}}\right)$ $95 \%$ 
Table 2. Components characterization.

\section{Component}

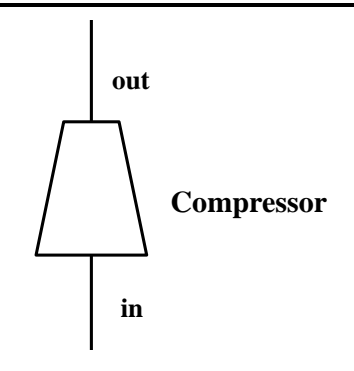

out
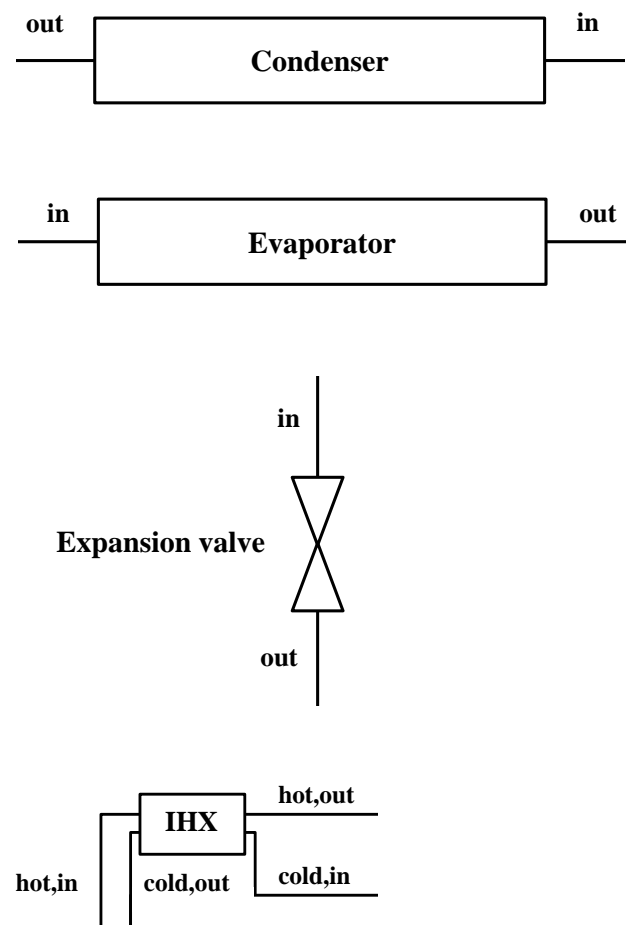

Expander $\begin{aligned} & \text { in } \\ & \end{aligned}$

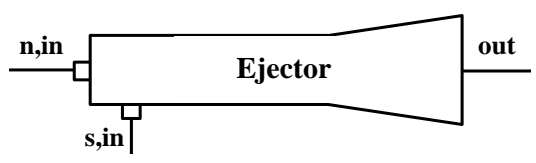

\section{Characteristic equations}

$$
\begin{gathered}
\eta_{i s, c}=\frac{h_{\text {out }, i s}-h_{i n}}{h_{\text {out }}-h_{\text {in }}} \\
\eta_{v, c}=\frac{\dot{m}_{c}}{\rho_{i} \cdot V \cdot N / 60}
\end{gathered}
$$$$
W_{c}=\eta_{\text {em }, c} \cdot \dot{m}_{c} \cdot\left(h_{\text {out }}-h_{\text {in }}\right)
$$

$$
Q_{k}=\dot{m}_{k} \cdot\left(h_{\text {in }}-h_{\text {out }}\right)
$$

$$
Q_{o}=\dot{m}_{o} \cdot\left(h_{\text {out }}-h_{\text {in }}\right)
$$

$$
h_{\text {in }}=h_{\text {out }}
$$

$$
\varepsilon=\frac{T_{\text {cold }, \text { out }}-T_{\text {cold }, \text { in }}}{T_{\text {hot }, \text { in }}-T_{\text {cold }, \text { in }}}
$$

$$
\begin{gathered}
\eta_{\text {is }, x}=\frac{h_{\text {in }}-h_{\text {out }}}{h_{\text {in }}-h_{\text {out }, \text { is }}} \\
W_{x}=\eta_{\text {em }, x} \cdot \eta_{v, x} \cdot \dot{m}_{x} \cdot\left(h_{\text {out }}-h_{\text {in }}\right)
\end{gathered}
$$

Calculation algorithm proposed by

Kornhauser [23] 